\title{
Attentional Performance in Children and Adolescents with Tic Disorder and Co-Occurring Attention-Deficit/Hyperactivity Disorder: New Insights from a $2 \times 2$ Factorial Design Study
}

\author{
Ellen Greimel • Sina Wanderer • \\ Aribert Rothenberger • Beate Herpertz-Dahlmann • \\ Kerstin Konrad • Veit Roessner \\ Published online: 18 February 2011 \\ (C) The Author(s) 2011. This article is published with open access at Springerlink.com
}

\begin{abstract}
The aim of the present study was to investigate the effect of both tic disorder (TD) and attention-deficit/hyperactivity disorder (ADHD) on attentional functions. $N=96$ children and adolescents participated in the study, including $n=21$ subjects with TD, $n=23$ subjects with ADHD, $n=25$ subjects with $\mathrm{TD}+\mathrm{ADHD}$, and $n=27$ controls. Attentional performance was tested based on four computerized attention tasks (sustained attention, divided attention, go/nogo and set shifting). The effect of TD as well as ADHD on attentional performance was tested using a $2 \times 2$ factorial approach. A diagnosis of TD had no negative impact on attentional functions but was associated with improved performance in the set shifting task. By contrast, regardless of a diagnosis of $\mathrm{TD}$, subjects with ADHD were found to perform worse in
\end{abstract}

E. Greimel $(\bowtie) \cdot$ K. Konrad

Child Neuropsychology Section, Department of Child and

Adolescent Psychiatry, Psychosomatics and Psychotherapy,

University Hospital of the RWTH Aachen,

52074 Aachen, Germany

e-mail: egreimel@ukaachen.de

E. Greimel · B. Herpertz-Dahlmann

Department of Child and Adolescent Psychiatry, Psychosomatics and Psychotherapy, University Hospital of the RWTH Aachen,

52074 Aachen, Germany

S. Wanderer $\cdot$ V. Roessner

Department of Child and Adolescent Psychiatry,

University Medical Center Dresden,

01309 Dresden, Germany

A. Rothenberger

Department of Child and Adolescent Psychiatry,

University Medical Center, University of Goettingen,

37075 Goettingen, Germany the sustained attention, divided attention and go/nogo task. No interaction effect between the factors TD and ADHD was revealed for any of the attention measures. Our results add to findings from other areas of research, showing that in subjects with TD and ADHD, ADHD psychopathology is often the main source of impairment, whereas a diagnosis of TD has little or no impact on neuropsychological performance in most cases and even seems to be associated with adaptive mechanisms.

Keywords Tic disorder - Attention-deficit/hyperactivity disorder $\cdot$ Comorbidity $\cdot$ Attention

\section{Introduction}

Chronic tic disorders (TD) including Tourette Syndrome are complex neurodevelopmental disorders that in most cases manifest before the age of 11 (Jankovic 2001). Psychiatric comorbidities are very common in TD. The majority of individuals with TD (up to 90\%) (Freeman et al. 2000) have at least one comorbid psychiatric disorder, with attention-deficit/hyperactivity disorder (ADHD) being the most frequent co-occurring condition ( $\sim 50 \%)$ (Freeman and Tourette Syndrome International Database Consortium 2007; Rothenberger et al. 2007). ADHD has been shown to substantially account for impairments in social, cognitive and school functioning in individuals comorbid with TD and ADHD (Spencer et al. 1999, 2001).

Although the nature of the frequent association between ADHD and TD has recently received increasing attention (Banaschewski et al. 2007; Yordanova et al. 2006), it is not yet fully understood. Depending on the domain examined 
(e.g., basic neurophysiology or neuropsychology), coexisting TD and ADHD can either be classified as a unique nosologic entity (interactive model), a combination of two independent pathological sources (additive model), or a phenotype expression of one of the two disorders (phenocopy hypothesis).

Particularly with regard to the domain of attention, results on the nature of comorbid ADHD and TD to date remain inconclusive. A number of studies that have investigated attentional functions in subjects with cooccurring TD and ADHD have revealed unexpected results as they have shown superior performance in participants comorbid with both disorders compared to participants with "ADHD only" in selective or sustained attention tasks (Greimel et al. 2008; Como 1993; Rothenberger et al. 2000). Based on the rationale that tics in persons supposedly affected by TD and ADHD may be misclassified as hyperactivity, it has been suggested that TD may produce behavioural symptoms of ADHD without the neurocognitive deficits that are usually associated with the latter disorder. In other words, results were frequently interpreted in support of the phenocopy hypothesis. An alternative explanation of the unexpected findings from these studies might be that persons with TD may possess mechanisms to compensate for attentional deficits associated with comorbid ADHD psychopathology (Leckman et al. 2006; Serrien et al. 2005). Importantly, owing to high comorbidity rates inherent to $\mathrm{TD}$, studies on attentional performance in co-existing TD and ADHD very rarely included a "pure" TD group. However, the inclusion of four groups (TD only, TD+ADHD, ADHD only, controls) is needed to unequivocally disentangle the effect of TD and ADHD on attentional task performance. The few studies that applied a four group design (Shin et al. 2001; Mahone et al. 2002; Sherman et al. 1998; Roessner et al. 2007a) have observed attentional impairments in individuals with ADHD and in individuals with TD+ADHD, while participants with TD were predominantly found to be unimpaired. Of note, these studies reported conflicting results as to whether subjects with TD+ADHD show superior performance on measures of attention compared to subjects suffering from ADHD only.

The inconsistency of findings on attentional performance in persons suffering from TD+ADHD might be in part due to the fact that previous studies often included further coexisting conditions that have been shown to substantially impact on attentional functions, such as conduct disorder (Pajer et al. 2008; Oosterlaan and Sergeant 1998) or obsessive-compulsive disorder (Ozonoff and Strayer 1998). Moreover, inconsistent results might also be attributable to substantial differences between the studies regarding the attentional paradigms applied (e.g., tasks on selective attention or sustained attention), since differential results might be expected depending on the attentional subdomain investigated. Hence, it seems important to investigate attentional performance based on a comprehensive test battery spanning several attentional capacities.

Knowledge of particular strengths and difficulties of individuals comorbid with TD and ADHD in the attention domain is crucial as it has important prognostic implications with regard to school and academic careers (Cavanna et al. 2009). Moreover, clarification of TD and ADHD comorbidity in the attention domain is highly relevant for diagnostic procedures and for optimizing treatment strategies (Döpfner and Rothenberger 2007).

Thus, the aim of the present study was to further elucidate TD and ADHD comorbidity in the attention domain by using a $2 \times 2$ factorial design with the factors TD (yes/no) and ADHD (yes/no). By including also participants with TD only, we aimed to extend previous research on attentional functions in co-occurring TD and ADHD. Moreover, in contrast to most previous studies, we excluded participants with further psychiatric comorbidities that have been frequently shown to influence attentional performance. To account for the possibility that differential results might be obtained depending on the attentional subdomain investigated, we applied four different tasks based on a well-established concept of attention (Van Zomeren and Brouwer 1994). Like many other models of attention, this concept distinguishes between selectivity and intensity of attention. Selectivity refers to the process that modulates responsiveness to specific stimuli constellations by giving priority to certain stimuli, whereas intensity describes the ability to activate and sustain attention over a prolonged time period. In addition, the concept includes a "supervisory attentional system" that is assumed to act as an executive control mechanism, modulating the two domains of selectivity and intensity (Van Zomeren and Brouwer 1994).

Based on a large body of literature, we hypothesized that a diagnosis of ADHD would be associated with attentional deficits in all domains of attention (Huang-Pollock and Nigg 2003; Willcutt et al. 2005; Jonkman 2005). By contrast, a diagnosis of TD was not expected to negatively impact on attentional task performance. No hypothesis was formulated concerning potential interaction effects between TD and ADHD because the literature has provided conflicting evidence on that issue (Roessner et al. 2007a; Shin et al. 2001; Sherman et al. 1998).

\section{Methods}

Participants A total of 96 children and adolescents participated in the study. The sample included 21 subjects with TD (19 with Tourette Syndrome, 2 with chronic tic 
disorder), 23 subjects with ADHD, 25 subjects with TD (19 with Tourette Syndrome, 6 with chronic tic disorder) and comorbid ADHD, and 27 typically developing subjects. Both subjects with chronic tic disorder and Tourette Syndrome were included in the study as the disorders presumably belong to the same spectrum and share similar cognitive profiles (Spencer et al. 1995). Age of participants ranged between 8 and 17 years. Only participants with an IQ above 80 (based on the CFT-20 (Weiß 1998) or WISCIII (Wechsler 1991; Tewes et al. 1999)) were included. Groups did not differ significantly in age, IQ, or sex proportion (all $p \mathrm{~s}>0.05$ ). Table 1 summarizes the demographic data of the study sample.

Clinical groups were recruited from the Departments of Child and Adolescent Psychiatry of the University Hospital of the RWTH Aachen and the University of Goettingen. They had been diagnosed by experienced clinicians according to ICD-10 (World Health Organization 1993) based on the developmental history, playroom observation, neurological and pediatric examinations and standardized behaviour rating scales. For screening and description of psychopathological symptoms across the clinical groups, the Child Behavior Checklist (CBCL, Achenbach 1993) was used. As the CBCL formed only part of the diagnostic assessment, no specified cut-off scores were used to determine the inclusion into the clinical groups. Standardized assessment of ADHD in all clinical groups also included a German parental report on ADHD symptoms (FBB-HKS) that has shown good psychometric quality comparable to the Conners rating scale (Döpfner and Lehmkuhl 1998; Erhart et al. 2008). The FBB-HKS can be used as a diagnostic checklist and assesses ADHD symptoms based on ICD-10 and DSM-IV, respectively. Participants with $>4$ symptoms of inattention and/or $>4$ symptoms of hyperactivity/impulsivity as assessed with the FBB-HKS were not included in the "pure" TD group. In subjects with TD, the Tourette's Syndrome Symptom List (Cohen et al. 1985) and the Yale Global Tic Severity Scale (Leckman et al. 1989) was applied to assess TD symptomatology.

CBCL internalizing, externalizing, and attention problems scores of the clinical groups are summarized in Table 1. As can be expected from previous research (Roessner et al. 2007a), comparison of CBCL scores based on ANOVAs revealed significant differences between the groups (Table 1, all $p \mathrm{~s}<0.05$ ). Subsequent post-hoc comparisons showed that internalizing problems were rated more severe in participants with TD+ADHD compared to participants with TD. Moreover, externalizing scores were higher in both the comorbid and ADHD group relative to

Table 1 Demographic data of clinical groups and controls

\begin{tabular}{|c|c|c|c|c|c|c|}
\hline & $\begin{array}{l}\text { Controls } \\
(n=27)\end{array}$ & $\begin{array}{l}\mathrm{TD} \\
(n=21)\end{array}$ & $\begin{array}{l}\text { ADHD } \\
(n=23)\end{array}$ & $\begin{array}{l}\text { ADHD+TD } \\
(n=25)\end{array}$ & $\begin{array}{l}\text { Group comparison } \\
p \text {-value }\end{array}$ & $\begin{array}{l}\text { Post-hoc } \\
\text { comparison }\end{array}$ \\
\hline Age (M, SD) & $12.0(1.5)$ & $11.3(1.6)$ & $11.9(1.9)$ & $11.7(2.3)$ & 0.57 & n.a. \\
\hline IQ (M, SD) & $104.8(9.5)$ & $105.8(11.8)$ & $101.0(9.2)$ & $99.8(11.9)$ & 0.17 & n.a. \\
\hline $\operatorname{Sex}(m / f)$ & $22 / 5$ & $15 / 6$ & $18 / 5$ & $20 / 5$ & 0.85 & n.a. \\
\hline \multicolumn{7}{|l|}{$\begin{array}{l}\text { Comorbid } \\
\text { diagnoses }\end{array}$} \\
\hline $\begin{array}{l}\text { Elimination } \\
\text { disorder (n) }\end{array}$ & n.a. & 0 & 0 & 1 & 0.54 & n.a. \\
\hline $\begin{array}{l}\text { Specific dev. } \\
\text { disorder }(n)^{a}\end{array}$ & n.a. & 2 & 4 & 1 & 0.31 & n.a. \\
\hline $\begin{array}{l}\text { Emotional disorder } \\
\text { child. (n) }\end{array}$ & n.a. & 1 & 0 & 1 & 0.59 & n.a. \\
\hline Specific phobia (n) & n.a. & 0 & 0 & 1 & 0.41 & n.a. \\
\hline \multicolumn{7}{|l|}{$\mathrm{CBCL}^{\mathrm{c}}$} \\
\hline Internalizing (M, SD) & n.a. & $51.7(10.6)$ & $57.6(12.2)$ & $61.2(10.7)$ & 0.03 & $\mathrm{ADHD}+\mathrm{TD}>\mathrm{TD} *$ \\
\hline Externalizing (M, SD) & n.a. & $48.1(9.9)$ & $59.4(11.0)$ & $61.9(7.3)$ & $<0.001$ & $\mathrm{ADHD}+\mathrm{TD} \& \mathrm{ADHD}>\mathrm{TD} *$ \\
\hline $\begin{array}{l}\text { Attention problems } \\
(\mathrm{M}, \mathrm{SD})\end{array}$ & n.a. & $57.4(6.1)$ & $63.1(8.2)$ & $69.9(11.4)$ & $<0.001$ & $\mathrm{ADHD}+\mathrm{TD}>\mathrm{TD} \& \mathrm{ADHD} *$ \\
\hline
\end{tabular}

$A D H D$ attention-deficit/hyperactivity disorder, $T D$ tic disorder; $f$ female; $m$ male; Emotional disorder child. emotional disorder with onset specific to childhood

${ }^{a}$ Specific developmental disorders included the following ICD-10 diagnoses: F81.0, F81.1, F82.0, F80.8

${ }^{b}$ Emotional disorders with onset specific to childhood included the following ICD-10 diagnoses: F93.0, F93.3

${ }^{\mathrm{c}}$ t-scores

${ }^{*} p<0.05$ (two-tailed) 
the TD group. Finally, attention problems were rated more severe in the TD+ADHD group compared to both the TD group and the ADHD group.

Participants with comorbid disorders that have been most frequently shown to substantially impact on neuropsychological test performance or general functioning (e.g., conduct disorder, oppositional defiant disorder, obsessivecompulsive disorder, pervasive developmental disorders, affective disorders, psychosis, posttraumatic stress disorder; see, e.g., Pajer et al. 2008; Oosterlaan and Sergeant 1998; Ozonoff and Strayer 1998; Stoddart et al. 2007) were not included in the current investigation. Participants comorbid with one of the following diagnoses were not excluded from the current study: elimination disorder, specific developmental disorders, emotional disorder with onset specific to childhood, or specific phobia. Clinical groups did not differ significantly in comorbidity rates of these disorders (all $p \mathrm{~s}>0.05$; Pearson's chi-square test; see Table 1 for details).

Control subjects were recruited via local schools, flyers and electronic mail announcements. These subjects were extensively screened to exclude psychiatric disorders using a semi-structured interview (K-DIPS) (Unnewehr et al. 1995). In addition, parents confirmed the absence of present tics or a lifetime history of tics as assessed via the respective section from the Kiddie-SADS-Present and Lifetime Version (K-SADS-PL) (Kaufman et al. 1997; German adaptation by Delmo et al. 2000).

Only participants who were free of medication at time of testing were included in the study. In participants who received stimulants ( 15 subjects in the ADHD, 8 subjects in the ADHD+TD group), these were deposed $48 \mathrm{~h}$ before testing.

Partial data from a subset of the sample have been reported previously (data from 13 controls; 12 subjects with ADHD; 7 subjects with ADHD+TD; Greimel et al. 2008). Note that in our previous study, no "TD only" group was included. Moreover, in contrast to our previous investigation, selection criteria in the current study were far more stringent (i.e., exclusion criteria for comorbidity and medication).

The study was approved by the institutional review boards and has been performed in accordance with the Declaration of Helsinki and in compliance with national legislation. All study participants were informed in detail about the protocol and the aims of the study, and written informed consent was obtained by at least one parent/legal custodian, after the parent(s)/legal custodian(s) had been informed about all aspects of the study.

Procedure A standardized computerized neuropsychological assessment was conducted based on two established neuropsychological test batteries (DeSonneville 2001; Fimm and Zimmermann 2001). The testing procedure lasted about
$40 \mathrm{~min}$. Participants received identical spoken instructions. The order of tasks was the same for all participants. To make sure that all participants were able to perform the tasks, all tasks were preceded by standardized practice trials.

Dependent Measures Based on the concept of attention by Van Zomeren and Brouwer (1994), four tasks were selected to assess different aspects of attentional performance. The intensity domain was assessed by a sustained attention task. A divided attention task was used to account for attention selectivity. The supervisory attentional system was tested with a set shifting task and a go/nogo paradigm.

Sustained Attention The sustained attention task involved the continuous and consecutive presentation of 50 series of twelve different dot patterns (600 signals; DeSonneville 2001). In each series, an equal number of 3-dot, 4-dot, or 5dot patterns were presented in a pseudo-random manner. The child was instructed to push the "yes" button with the dominant hand whenever a 4-dot pattern (target) was presented, and to press the "no" button with the nondominant hand if the presented pattern contained three or five dots (non-targets). The dependent measures of the sustained attention task were the reaction time (RT, median), the within-subject standard deviation (SD) of $\mathrm{RTs}$, and the number of errors.

Divided Attention Divided attention was assessed based on a dual task that combined an optic and acoustic discrimination task (Fimm and Zimmermann 2001). Children were asked to respond as quickly as possible whenever a square appeared and also if an alternating high and deep tone was repeated. 100 visual and 200 acoustic stimuli were presented containing 17 visual and 16 acoustic target trials. RT (median), within-subject SD of RTs, and number of errors were entered into the statistical analysis.

Go/nogo In the go/nogo paradigm (Fimm and Zimmermann 2001), a motor response with the dominant hand was either initiated (go) or inhibited (nogo) depending on whether an " $\mathrm{x}$ " (go) or a "+" (nogo) stimulus appeared on the monitor. The go/nogo task comprised 40 trials with $50 \%$ go trials. Visual stimuli appeared in random order with a variable intertrial interval. The relevant dependent measures were the RT (median) and the within-subject SD of RTs, and the number of errors.

Visual Set Shifting In the set shifting task (DeSonneville 2001), the signal was a bar with a coloured square, which jumped from left to right and vice versa. The square changed its colour from red to green or from green to red. Depending on the colour of the square after the jump, the child had to copy the movement of the square (compatible 
condition), or was required to mirror the movement of the square (e.g., press the left key in response to a rightward movement; incompatible condition). 70 trials were presented, including 35 incompatible and 35 compatible trials. The dependent measures comprised the number of errors and the RT, separated for compatible and incompatible trials.

\section{Statistical Analysis}

The data was analyzed using PASW 18 (SPSS Inc.). For descriptive purpose and to facilitate comparison with previous findings (Shin et al. 2001; Mahone et al. 2002; Sherman et al. 1998; Roessner et al. 2007a), means and SDs of neuropsychological task parameters of the three clinical and the control group were computed. All subsequent analyses were based on a $2 \times 2$ factorial approach with the factors TD (yes/no) and ADHD (yes/no). A $2 \times 2$ factorial multivariate analysis of covariance (MANCOVA) with TD and ADHD as between-subject factors, age as a covariate, and neuropsychological test scores as the dependent variables was conducted. A multivariate approach was chosen for the analysis of attentional performance since several parameters within and between the four tasks correlated substantially $(p<0.05)$ across subjects. Age was included as a covariate since correlation analyses revealed that this variable was significantly related to 8 out of 14 attentional parameters. IQ only correlated significantly with one parameter (within-subject SD in the sustained attention task) and was therefore not included as a second covariate (see Stevens 2002, for a comprehensive view on the use of covariates for the purpose of error variance reduction).

The MANCOVA was followed by $2 \times 2$ factorial analyses of covariance (ANCOVAs) with the factors TD and ADHD, and age as a covariate. Generally, significant interactions between the factors TD and ADHD in the MANCOVA and ANCOVAs would argue against an additive model. Effect sizes for the factors TD, ADHD and the interaction TDxADHD were calculated using partial eta squared $\left(\eta_{\mathrm{p}}^{2}\right)$.

In the case of a significant main effect of TD or ADHD on error or RT parameters in the ANCOVAs, we examined the possibility that the effect was driven by differential speed-accuracy trade-off patterns. Therefore, correlations between the errors and the RTs of the respective task were calculated separately for each level of the factor that caused the significant main effect (e.g., ADHD yes versus ADHD no). Subsequently, the correlations were compared using Fisher's $\mathrm{Z}$ transformation.

In addition to the $2 \times 2$ categorical approach taken, we performed an exploratory data analysis to assess the influence of ADHD symptomatology on neuropsychological performance data using a dimensional approach. For this purpose, T-scores of the CBCL attention problem scale (Biederman et al. 1993; Chen et al. 1994) were correlated with attentional parameters in all subjects with a diagnosis of TD and/or ADHD. As this additional analysis was explorative in nature and was used to confirm the results of the $2 \times 2$ analysis, no adjustments for multiple comparisons were made.

\section{Results}

For descriptive purpose, means and SDs of neuropsychological task parameters of the three clinical and the control group are summarized in Table 2. The MANCOVA with all dependent measures of the four attention paradigms revealed a significant main effect of $\operatorname{ADHD}(F(13,79)=$ 2.54, $\left.p<0.01, \eta_{\mathrm{p}}^{2}=0.30\right)$. Neither the main effect of TD (F $\left.(13,79)=0.69, p=0.77, \eta_{\mathrm{p}}^{2}=0.10\right)$ nor the interaction $\mathrm{TD} \times \operatorname{ADHD}\left(\mathrm{F}(13,79)=0.53, p=0.90, \eta_{\mathrm{p}}^{2}=0.08\right)$ proved to be significant.

Follow-up ANCOVAs revealed significant main effects of ADHD on several parameters. The diagnosis of ADHD had a significant effect on both the number of errors $(\mathrm{F}(1$, $\left.91)=6.72, p=0.01, \eta_{\mathrm{p}}^{2}=0.07\right)$ and within-subject SD of RTs $\left(\mathrm{F}(1,91)=6.42, p=0.01, \eta_{\mathrm{p}}^{2}=0.07\right)$ in the sustained attention task. As can be seen from Fig. 1a and b, a diagnosis of ADHD was associated with more errors and larger SD of RTs in this task. The effect of ADHD on the RT in the sustained attention task reached only marginal significance $\left(\mathrm{F}(1,91)=3.56, p=0.06, \eta_{\mathrm{p}}^{2}=0.04\right)$, with a trend for longer RTs in subjects with ADHD (1119.3 \pm 317.6) than in subjects without ADHD (1049.8 \pm 205.2$)$. A main effect of ADHD was also revealed for the RT in the go/nogo task $\left(\mathrm{F}(1,91)=6.57, p=0.01, \eta_{\mathrm{p}}^{2}=0.07\right)$, with ADHD being associated with longer RTs (Fig. 1c). Moreover, a main effect of ADHD was found for the RT in the divided attention task $\left(\mathrm{F}(1,91)=6.98, p=0.01, \eta_{\mathrm{p}}^{2}=0.07\right)$. Again, the diagnosis of ADHD was associated with longer RTs (Fig. 1d). Finally, marginal significant main effects of ADHD were revealed for the RT $(\mathrm{F}(1,91)=2.96, p=0.09$, $\eta_{\mathrm{p}}^{2}=0.03$; see also Fig. 1e) and errors $(\mathrm{F}(1,91)=3.08, p=$ $0.08, \eta_{\mathrm{p}}^{2}=0.03$ ) during incompatible trials in the set shifting task. Regardless of a diagnosis of TD, subjects with ADHD tended to have longer RTs $(1124.2 \pm 314.9)$ and to commit more errors $(10.1 \pm 7.0)$ than subjects without ADHD (1041.0 \pm 315.9 for RTs; $7.9 \pm 5.7$ for errors). No significant main effect of ADHD was shown for the remaining attention parameters (all $p \mathrm{~s}>0.05$ ).

The diagnosis of TD had a significant impact on the RT during incompatible trials in the set shifting task $(\mathrm{F}(1,91)=$ $\left.5.25, p=0.02, \eta_{\mathrm{p}}^{2}=0.06\right)$. Interestingly, RTs in participants 
Table 2 Neuropsychological test performance of clinical groups and control subjects

$A D H D$ attention-deficit/hyperactivity disorder, $T D$ tic disorder

\begin{tabular}{lcccc}
\hline & Controls $(n=27)$ & TD $(n=21)$ & ADHD $(n=23)$ & ADHD+TD $(n=25)$ \\
\hline Sustained Attention & & & & \\
RT & $1073.0(183.1)$ & $1019.9(231.8)$ & $1126.9(337.5)$ & $1112.3(305.1)$ \\
SD & $436.0(177.6)$ & $418.1(212.3)$ & $515.1(255.6)$ & $534.3(279.5)$ \\
Errors & $42.3(26.4)$ & $51.7(28.4)$ & $64.7(32.4)$ & $61.7(32.0)$ \\
Go/Nogo & & & & \\
RT & $427.5(67.8)$ & $404.5(89.7)$ & $452.7(114.4)$ & $456.9(103.4)$ \\
SD & $102.4(30.5)$ & $104.8(30.2)$ & $127.0(93.9)$ & $110.8(27.7)$ \\
Errors & $8.8(5.5)$ & $13.2(9.8)$ & $12.6(10.7)$ & $12.0(10.2)$ \\
Divided Attention & & & & \\
RT & $731.9(68.5)$ & $733.3(109.9)$ & $780.4(146.3)$ & $790.6(162.2)$ \\
SD & $271.3(93.1)$ & $260.7(91.0)$ & $274.2(92.7)$ & $314.9(156.8)$ \\
Errors & $6.5(2.5)$ & $6.9(4.3)$ & $8.2(5.1)$ & $8.6(8.9)$ \\
Set Shifting & & & & $1062.0(343.2)$ \\
RT compatible & $1085.5(352.7)$ & $956.2(306.8)$ & $1083.7(263.3)$ & $1086.1(333.5)$ \\
RT incompatible & $1107.7(344.8)$ & $955.2(257.2)$ & $1165.7(295.0)$ & $9.0(5.4)$ \\
Errors compatible & $7.1(5.1)$ & $9.3(7.4)$ & $7.6(6.2)$ & $10.9(6.7)$ \\
Errors incompatible & $7.3(4.3)$ & $8.7(7.1)$ & $9.3(7.4)$ & \\
\hline
\end{tabular}

a) Sustained attention: Errors

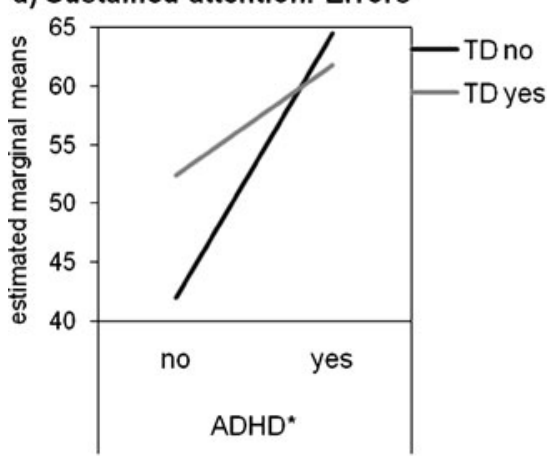

d) Divided attention: RT

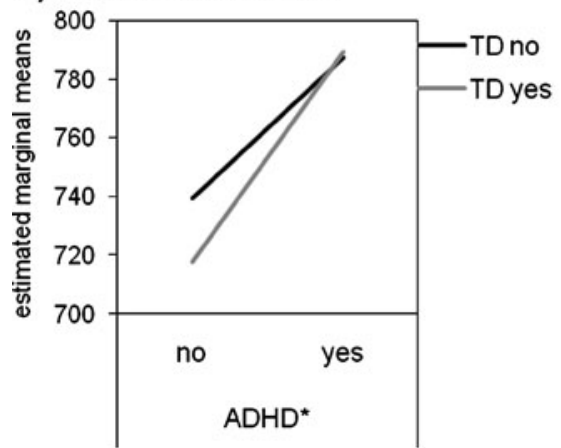

b) Sustained attention: SD of RTs

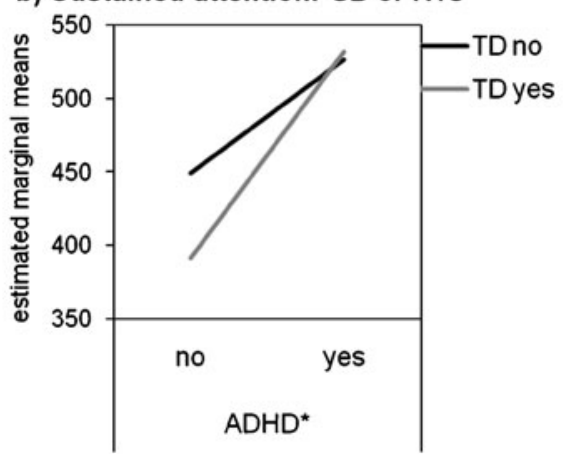

e) Set shifting: RT for incompatible trials

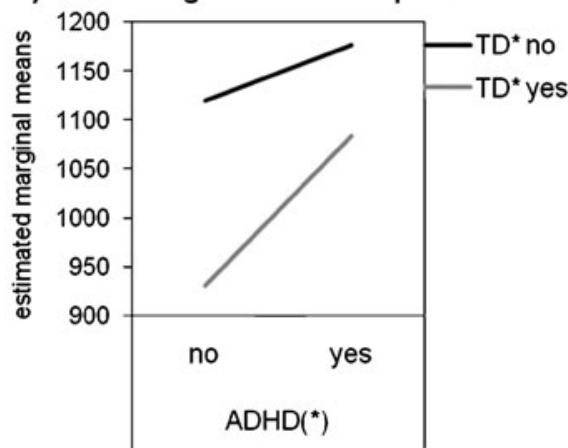

c) Go/nogo: RT

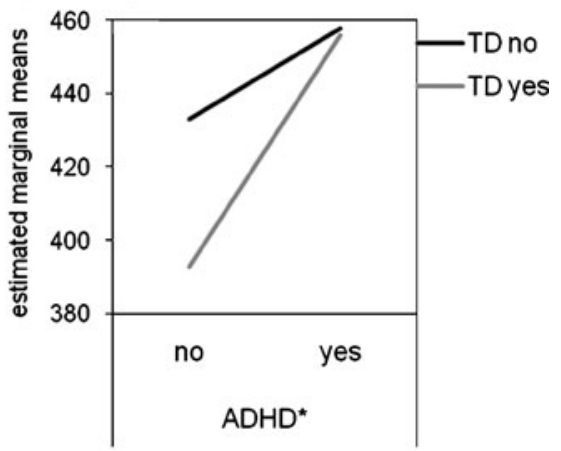

Fig. 1 Profile plots of a errors in the sustained attention task, b within-subject standard deviation of reaction times in the sustained attention task, $\mathbf{c}$ reaction time in the go/nogo task, $\mathbf{d}$ reaction time in the divided attention task, and e reaction time for incompatible trials in the set shifting task (separated by group and corrected for age). $A D H D$ attention-deficit/hyperactivity disorder; $T D$ tic disorder; $S D$ standard deviation; $R T$ reaction time. $\left.{ }^{*} p<0.05 ;{ }^{*}\right) p<0.10$ 
with TD were shorter as compared to participants without TD (Fig. 1e). No main effect of TD on any other attentional parameter was found (all $p \mathrm{~s}>0.05$ ). Moreover, no significant interaction between TD and ADHD was revealed for any of the neuropsychological task parameters (all $p \mathrm{~s}>0.05$ ).

To examine whether the significant main effects of ADHD on RTs and error parameters in the sustained attention task, the go/nogo task and the divided attention task were driven by distinct speed-accuracy trade-off patterns, correlations between errors and RTs for each task were calculated separately for subjects with and without a diagnosis of ADHD, and subsequently compared using Fisher's Z transformation. Correlations between RTs and errors in the sustained attention and divided attention task were all non-significant (all $p \mathrm{~s}>0.05$ ) and did not significantly differ between subjects with and without ADHD (all $p \mathrm{~s}>0.05$ ). Conversely, significant correlations between RTs and errors in the go/nogo task were revealed for both subjects with ADHD $(r=-0.48, p<0.01)$ and subjects without a diagnosis of ADHD $(r=-0.32 ; p=0.03)$, indicating speed-accuracy trade-offs. Importantly, however, correlation coefficients did not significantly differ between subjects with and without ADHD $(p=0.38)$, suggesting that the significant main effect of ADHD was not accounted for by differences in the speed-accuracy trade-off patterns between subjects assigned to the two factor levels.

Similarly, we examined whether the significant main effect of TD on RT during incompatible trials in the set shifting task was attributable to differential speed-accuracy trade-off patterns in subjects with versus without TD. Correlations between RTs and errors for the incompatible condition were non-significant (all $p \mathrm{~s}>0.05$ ) and did not significantly differ between subjects assigned to the two factor levels $(p=0.18)$.

Correlational analyses between attentional performance data and ADHD symptomatology in subjects with TD and/ or ADHD revealed a significant relationship between CBLC attention problem scores and within-subject SD of RTs in the sustained attention task $(r=0.27, p=0.03)$. A marginal significant correlation was found between attention problem scores and RTs in this task $(r=0.25, p=0.05)$. Moreover, attention problem scores correlated significantly with RTs in the go/nogo task $(r=0.30, p=0.02)$, SD of RTs $(r=0.44, p<0.001)$ and errors $(r=0.44, p<0.001)$ in the divided attention task. No significant correlations were obtained for the remaining parameters (all $p \mathrm{~s}>0.05$ ).

\section{Discussion}

The aim of the present study was to disentangle the influence of TD and ADHD on attentional performance in unmedicated individuals suffering from TD+ADHD based on a $2 \times 2$ factorial design. In sum, as expected, we found that the diagnosis of ADHD was associated with impaired attentional functions: regardless of a diagnosis of $\mathrm{TD}$, participants with ADHD were found to perform worse in tasks related to the supervisory attentional system, the selectivity domain and the intensity domain of attention. Also in line with our hypothesis, a diagnosis of TD had no negative impact on attentional task parameters; participants with TD even outperformed individuals without a diagnosis of TD in the set shifting task. We found no interaction effect between the factors TD and ADHD on any of the attention measures. This finding is congruent with an additive model of comorbidity, suggesting that co-existing TD and ADHD can be regarded as a combination of two independent pathological components.

The absence of impairment found in our measures of attention in TD adds to a growing number of studies that have reported unimpaired attentional functions in subjects with TD when psychiatric comorbidities are carefully controlled for (Roessner et al. 2008; Ozonoff and Strayer 1998; Shin et al. 2001; Sherman et al. 1998). Together, these findings suggest that earlier reports of deficient attentional capacity in TD (Bornstein 1991; Channon et al. 1992) are likely to be explained by the fact that comorbid conditions, such as ADHD, were not systematically accounted or screened for. Somewhat unexpectedly, participants with TD even outperformed participants without TD in the set shifting task which was used to account for the supervisory attentional system. In this task, a diagnosis of TD was associated with faster responses in incompatible trials, indicating enhanced executive control in this particularly effortful condition. Our finding is in line with earlier reports of increased general cognitive functioning in uncomplicated TD, e.g., as evidenced by unexpectedly high IQ scores (e.g., Denckla 2006). Interestingly, there are some previous reports of increased cognitive control mechanisms in subjects with TD when task demands are maximal (Jackson et al. 2007; Mueller et al. 2006). The good task performance in the set shifting task in TD subjects might perhaps be explained by increased prefrontal control mechanisms associated with the disorder ("frontal lobe compensation hypothesis") (Leckman et al. 2006). An EEG study by Serrien et al. (2005) could show that elevated prefrontal control mechanisms in individuals with TD are likely to be involved in the voluntary suppression of tics and are adaptive with regard to the performance in an executive control task. Moreover, it has been suggested that elevated cognitive control mechanisms in TD might perhaps be linked to dopaminergic hypertransmission in affected individuals (Baym et al. 2008; Vicario et al. 2010; Albin and Mink 2006). In future studies, it would be of great interest to apply multimodal imaging strategies including Positron Emission Tomography to determine how altered dopaminergic function might relate to elevated prefrontal control mechanisms and behavioural performance in TD. 
Together with the results from the present study, the idea of compensatory consequences in TD subjects may help to explain why previous studies that included groups of subjects with ADHD and subjects with co-existing ADHD and TD (but no "pure" TD group) reported superior attentional performance in the comorbid compared to the ADHD group (Greimel et al. 2008; Como 1993; Rothenberger et al. 2000). More precisely, in the comorbid groups, adaptive mechanisms related to TD might have ameliorated attentional performance deficits associated with ADHD in some individuals.

In the present investigation we observed an impairing effect of ADHD in the sustained attention, go/nogo, and divided attention task. These findings are consistent with a large body of literature on deficits in ADHD across all domains of attention (for an overview see Huang-Pollock and Nigg 2003; Willcutt et al. 2005; Jonkman 2005), although findings on the selectivity aspect of attention in ADHD have been mixed (Manly et al. 2001; De Shazo Barry et al. 2004). It needs to be discussed that - although a deficit in executive control has been claimed to be central to ADHD (Doyle 2006) — we only found a trend towards a negative impact of ADHD on task parameters in the set shifting task, the second task used to test the supervisory attentional system/executive control mechanisms. However, our results are well in line with a meta-analysis on executive function deficits in ADHD reporting most consistent and strongest effects for executive deficits in response inhibition (as tested by the go/nogo task), whereas effects are substantially smaller and less robust for set shifting tasks (Willcutt et al. 2005).

Exploratory correlational analyses between CBCL attention problem scores and neuropsychological performance data across all clinical groups confirmed that ADHD symtomatology was associated with worse attentional performance in the sustained attention, go/ nogo and divided attention task. In future studies, it would be of great interest to extend this dimensional approach and to account for the continuous nature of both ADHD and TD by applying dimensional measures of both disorders in all subjects.

It is of interest that attention problems in the CBCL were rated as more severe in the $\mathrm{ADHD}+\mathrm{TD}$ group compared to the ADHD group. However, this is not surprising since the CBCL attention problem scale contains not only items that tap on attentional problems but also some items related to tic disorders or movement disorders in general (Pierre et al. 1999; Piek et al. 2010). Indeed, an exploratory post-hoc analysis confirmed that higher scores in the ADHD+TD compared to the ADHD group were almost exclusively observed on items of the attention problem scale that can be linked to movement abnormalities (e.g., "can't sit still" or "nervous movements/twitching").
A limitation of the present study is that in the clinical groups, the diagnoses of ADHD and TD and further comorbid conditions were not assessed based on standardized diagnostic interviews. Although participants in our sample had been diagnosed by experienced clinicians based on comprehensive clinical information and rating scales, in future studies, it would undoubtedly be advantageous to use diagnostic instruments like the K-DIPS (Unnewehr et al. 1995) or the Kiddie-SADS (Kaufman et al. 1997) not only in controls but also in the clinical groups. Given that learning disabilities are frequent in individuals with ADHD and/or TD (Barkley 2006; Burd et al. 2001), future studies should also systematically assess learning disabilities based on standardized tests. Moreover, individuals with ADHD and/or TD were clinically referred and thus may not be representative of individuals in the community suffering from these disorders. In the same vein, it should be mentioned that we excluded participants with comorbid obsessive-compulsive disorder and other comorbidities that have been robustly shown to impact on neuropsychological test performance. As the excluded comorbid conditions, particularly obsessive-compulsive disorder, frequently cooccur with TD (Gaze et al. 2006; Peterson et al. 2001), our study group is less representative of the population of individuals with TD.

Despite these caveats, the present study provides important new insights into the interplay between TD and ADHD in the domain of attention. We found that in participants comorbid with both disorders, only ADHD, but not TD, exerts a negative influence on attentional functions. The absence of an interaction effect between ADHD and TD on attentional performance is congruent with an additive model of comorbidity, which has also been advocated to apply for other neuropsychological abilities (Roessner et al. 2007a), for the level of psychopathology (Gadow et al. 2002; Roessner et al. 2007b) and basic neurophysiology, such as sleep-wave regulation (Kirov et al. 2007) or motor excitability (Moll et al. 2001).

Our results add to previous findings showing that in TD, comorbid disorders often are far more impairing than the tics themselves with regard to functioning in several areas, including general cognitive, academic and social skills (Spencer et al. 2001; Roessner et al. 2007b). An important clinical implication of the present investigation might be that the treatment of ADHD should be given priority in most individuals comorbid with TD and ADHD to avoid maladjustment in social and academic life (Jankovic 2001). Exceptions from this rule are obvious, e.g., in persons with very severe and disabling tics, or if tics lead to secondary neurologic complications. An important future research field would be to further shed light on adaptive mechanisms in TD when co-occurring with ADHD and to elucidate whether and how interven- 
tion strategies could foster and make use of such adaptive mechanisms to improve the outcome in individuals affected by both disorders.

Acknowledgments We thank the participants with their families who took part in the study. Moreover, we want to thank our colleagues Astrid Puetz-Ebert, Thomas Guenther (Aachen), and Bjoern Albrecht (Goettingen) for their helpful support.

Open Access This article is distributed under the terms of the Creative Commons Attribution Noncommercial License which permits any noncommercial use, distribution, and reproduction in any medium, provided the original author(s) and source are credited.

\section{References}

Achenbach, T. M. (1993). Empirically based taxonomy: how to use syndromes and profile types derived from the CBCL from 4 to 18 , $T R F$, and WSR. Burlington: University of Vermont, Department of Psychiatry.

Albin, R. L., \& Mink, J. W. (2006). Recent advances in Tourette syndrome research. Trends in Neurosciences, 29, 175-182.

Banaschewski, T., Neale, B. M., Rothenberger, A., \& Roessner, V. (2007). Comorbidity of tic disorders \& ADHD. European Child and Adolescent Psychiatry, 16, I/5-I/14.

Barkley, R. A. (2006). Associated cognitive, developmental, and health problems. In R. A. Barkley (Ed.), Attention-deficit hyperactivity disorder: A handbook for diagnosis and treatment (pp. 184-218). New York: Guildford.

Baym, C. L., Corbett, B. A., Wright, S. B., \& Bunge, S. A. (2008). Neural correlates of tic severity and cognitive control in children with Tourette syndrome. Brain, 131, 165-179.

Biederman, J., Faraone, S. V., Doyle, A., Lehman, B. K., Kraus, I., Perrin, J., et al. (1993). Convergence of the Child Behavior Checklist with structured interview-based psychiatric diagnoses of ADHD children with and without comorbidity. Journal of Child Psychology and Psychiatry, 34, 1241-1251.

Bornstein, R. A. (1991). Neuropsychological performance in adults with Tourette's syndrome. Psychiatry Research, 37, 229-236.

Burd, L., Kerbeshian, J., Barth, A., Klug, M. G., Avery, P. K., \& Benz, B. (2001). Long-term follow-up of an epidemiologically defined cohort of patients with Tourette syndrome. Journal of Child Neurology, 16, 431-437.

Cavanna, A. E., Servo, S., Monaco, F., \& Robertson, M. M. (2009). The behavioral spectrum of Gilles de la Tourette syndrome. Journal of Neuropsychiatry and Clinical Neurosciences, 21, 13-23.

Channon, S., Flynn, D., \& Robertson, M. M. (1992). Attentional deficits in Gilles de la Tourette syndrome. Neuropsychiatry, Neuropsychology, and Behavioral Neurology, 5, 170-177.

Chen, W. J., Faraone, S. V., Biederman, J., \& Tsuang, M. T. (1994). Diagnostic accuracy of the Child Behavior Checklist scales for attention-deficit hyperactivity disorder: a receiver-operating characteristic analysis. Journal of Consulting and Clinical Psychology, 62, 1017-1025.

Cohen, D. J., Leckman, J. F., \& Shaywitz, B. A. (1985). The Tourette Syndrome and other tics. In D. Shaffer, A. A. Ehrhardt, \& L. L. Greenhill (Eds.), The clinical guide to child psychiatry (pp. 326). New York: Free Press.

Como, P. G. (1993). Neuropsychological testing. In R. Kurlan (Ed.), Handbook of Tourette's syndrome and related tic and behavioral disorders (pp. 221-239). New York: Marcel Dekker.
De Shazo Barry, T., Grofer Klinger, L., Lyman, R. D., Bush, D., \& Hawkins, L. (2004). Visual selective attention versus sustained attention in boys with Attention-Deficit/ Hyperactivity Disorder. Journal of Attention Disoders, 4, 193-202.

Delmo, C., Weiffenbach, O., Gabriel, M., \& Poustka, F. (2000). 3. Auflage der deutschen Forschungsversion des K-SADS-PL, erweitert um ICD-10-Diagnostik. Bern: Huber.

Denckla, M. B. (2006). Attention-deficit hyperactivity disorder (ADHD) comorbidity: a case for "pure" Tourette syndrome. Journal of Child Neurology, 21, 701-703.

DeSonneville, L. M. J. (2001). ANT 2.1 Amsterdam Neuropsychological Tasks, Manual. Amstelveen: Sonar.

Döpfner, M., \& Lehmkuhl, G. (1998). Diagnostik-System für psychische Störungen im Kindes- und Jugendalter nach ICD-10 und DSM-IV. Bern: Huber.

Döpfner, M., \& Rothenberger, A. (2007). Behavior therapy in ticdisorders with co-existing ADHd. European Child and Adolescent Psychiatry, 16, I/89-I/99.

Doyle, A. E. (2006). Executive functions in attention-deficit/ hyperactivity disorder. Journal of Clinical Psychiatry, 67, 2126.

Erhart, M., Doepfner, M., Ravens-Sieberer, U., \& The Bella study group. (2008). Psychometric properties of two ADHD questionnaires: comparing the Conners' scale and the FBB-HKS in the general population of German children and adolescents - results of the BELLA study. European Child and Adolescent Psychiatry, 17, 106-115.

Fimm, B., \& Zimmermann, P. (2001). Testbatterie zur Aufmerksamkeitsprüfung (TAP)-Version 1.6. Herzogenrath: Psytest.

Freeman, R. D., \& Tourette Syndrome International Database Consortium. (2007). Tic disorders and ADHD: answers from a world-wide clinical dataset on Tourette syndrome. European Child and Adolescent Psychiatry, 16, I/15-I/23.

Freeman, R. D., Fast, D. K., Burd, L., Kerbeshian, J., Robertson, M. M., \& Sandor, P. (2000). An international perspective on Tourette syndrome: selected findings from 3,500 individuals in 22 countries. Developmental Medicine \& Child Neurology, 42, 436-447.

Gadow, K. D., Nolan, E. E., Sprafkin, J., \& Schwartz, J. (2002). Tics and psychiatric comorbidity in children and adolescents. Developmental Medicine \& Child Neurology, 44, 330-338.

Gaze, C., Kepley, H. O., \& Walkup, J. T. (2006). Co-occurring psychiatric disorders in children and adolescents with Tourette syndrome. Journal of Child Neurology, 21, 657-664.

Greimel, E., Herpertz-Dahlmann, B., Günther, T., Vitt, C., \& Konrad, K. (2008). Attentional functions in children and adolescents with attention-deficit/hyperactivity disorder with and without comorbid tic disorder. Journal of Neural Transmission, 115, 191-200.

Huang-Pollock, C. L., \& Nigg, J. T. (2003). Searching for the attention deficit in attention deficit hyperactivity disorder: the case of visuospatial orienting. Clinical Psychology Review, 23, 801-830.

Jackson, G., Mueller, S., Hambleton, K., \& Hollis, C. (2007). Enhanced cognitive control in Tourette Syndrome during task uncertainty. Experimental Brain Research, 182, 357-364.

Jankovic, J. (2001). Tourette's Syndrome. New England Journal of Medicine, 345, 1184-1192.

Jonkman, L. M. (2005). Selective attention deficits in children with attention deficit hyperactivity disoder. A review of behavioral and electrophysiological studies. In D. Gozal \& D. L. Molfese (Eds.), Attention deficit hyperactivity disorder. From genes to patients (pp. 255-275). Totowa: Humana.

Kaufman, J., Birmaher, B., Brent, D., Rao, U., Flynn, C., Moreci, P., et al. (1997). Schedule for affective disorders and schizophrenia for school-age children - present and lifetime version (K-SADSPL): initial reliability and validity data. Journal of the American Academy of Child and Adolescent Psychiatry, 36, 980-988. 
Kirov, R., Kinkelbur, J., Banaschewski, T., \& Rothenberger, A. (2007). Sleep patterns in children with attention-deficit/hyperactivity disorder, tic disorder and comorbidity. The Journal of Child Psychology and Psychiatry, 48, 561-570.

Leckman, J. F., Riddle, M. A., Hardin, M. T., Ort, S. I., Swartz, K. L., Stevenson, J. O. H. N., et al. (1989). The Yale Global Tic Severity Scale: initial testing of a clinician-rated scale of tic severity. Journal of the American Academy of Child \& Adolescent Psychiatry, 28, 566-573.

Leckman, J. F., Vaccarino, F. M., Kalanithi, P. S. A., \& Rothenberger, A. (2006). Annotation: Tourette syndrome: a relentless drumbeat - driven by misguided brain oscillations. Journal of Child Psychology and Psychiatry, 47, 537-550.

Mahone, E. M., Cirino, P. T., Cutting, L. E., Cerrone, P. M., Hagelthorn, K. M., Hiemenz, J. R., et al. (2002). Validity of the behavior rating inventory of executive function in children with $\mathrm{ADHD}$ and/or Tourette syndrome. Archives of Clinical Neuropsychology, 17, 643662.

Manly, T., Anderson, V., Nimmo-Smith, I., Turner, A., Watson, P., \& Robertson, I. H. (2001). The differential assessment of children's attention: the test of everyday attention for children (TEA-Ch), Normative sample and ADHD performance. Journal of Child Psychology and Psychiatry, 42, 1065-1081.

Moll, G. H., Heinrich, H., Trott, G. E., Wirth, S., Bock, N., \& Rothenberger, A. (2001). Children with comorbid attentiondeficit-hyperactivity disorder and tic disorder: evidence for addititve inhibitory deficits within the motor system. Annals of Neurology, 49, 393-396.

Mueller, S. C., Jackson, G. M., Dhalla, R., Datsopoulos, S., \& Hollis, C. P. (2006). Enhanced cognitive control in young people with Tourette's syndrome. Current Biology, 16, 570-573.

Oosterlaan, J., \& Sergeant, J. A. (1998). Response inhibition and response re-engagement in attention-deficit/hyperactivity disorder, disruptive, anxious and normal children. Behavioural Brain Research, 94, 33-43.

Ozonoff, S., \& Strayer, D. L. (1998). Inhibitory deficits in Tourette syndrome: a function of comorbidity and symptom severity. Journal of Child Psychiatry, 39, 1109-1118.

Pajer, K., Chung, J., Leininger, L., Wang, W., Gardner, W., \& Yeates, K. (2008). Neuropsychological function in adolescent girls with conduct disorder. Journal of the American Academy of Child \& Adolescent Psychiatry, 47, 416-425.

Peterson, B. S., Pine, D. S., Cohen, P. A. T. R., \& Brook, J. S. (2001). Prospective, longitudinal study of tic, obsessive-compulsive, and attention-deficit/hyperactivity disorders in an epidemiological sample. Journal of the American Academy of Child \& Adolescent Psychiatry, 40, 685-695.

Piek, J. P., Barrett, N. C., Dyck, M. J., \& Reiersen, A. M. (2010). Can the child behavior checklist be used to screen for motor impairment? Developmental Medicine \& Child Neurology, 52, 200-204.

Pierre, C. B., Nolan, E. E., Gadow, K. D., Kenneth, D., Sverd, J., \& Sprafkin, J. (1999). Comparison of internalizing and externalizing symptoms in children with attention-deficit hyperactivity disorder with and without comorbid tic disorder. Journal of Developmental and Behavioral Pediatrics, 20, 170-176.

Roessner, V., Becker, A., Banaji, M. R., \& Rothenberger, A. (2007a). Executive functions in children with chronic tic disorders with/ without ADHD: new insights. European Child and Adolescent Psychiatry, 16, 36-44.

Roessner, V., Becker, A., Banaschewski, T., \& Rothenberger, A. (2007b). Psychopathological profile in children with chronic tic disorder and co-existing adhd: additive effects. Journal of Abnormal Child Psychology, 35, 79-85.

Roessner, V., Albrecht, B., Dechent, P., Baudewig, J., \& Rothenberger, A. (2008). Normal response inhibition in boys with Tourette syndrome. Behavioral and Brain Functions, 4.
Rothenberger, A., Banaschewski, T., Heinrich, H., Moll, G. H., Schmidt, M. H., \& van't Klooster, B. (2000). Comorbidity in ADHD-children: effects of coexisting conduct disorder or tic disorder on event-related brain potentials in an auditory selectiveattention task. European Archives of Psychiatry and Clinical Neuroscience, 250, 101-110.

Rothenberger, A., Roessner, V., Banaschewski, T., \& Leckman, J. F. (2007). Co-existence of tic disorders and attention-deficit/hyperactivity disorder-recent advances in understanding and treatment. European Child and Adolescent Psychiatry, 16, I/1-I/4.

Serrien, D. J., Orth, M., Evans, A. H., Lees, A. J., \& Brown, P. (2005). Motor inhibition in patients with Gilles de la Tourette syndrome: functional activation pattern as revealed by EEG coherence. Brain, 128, 116-125.

Sherman, E. M. S., Shepard, L., Joschko, M., \& Freeman, R. D. (1998). Sustained attention and impulsivity in children with Tourette syndrome: comorbidity and confounds. Journal of Clinical and Experimental Neuropsychology, 20, 644-657.

Shin, M. S., Chung, S. J., \& Hong, K.-E. M. (2001). Comparative study of the behavioral and neuropsychologic characteristics of tic disorder with or without attention-deficit hyperactivity disorder (ADHD). Journal of Child Neurology, 16, 719-726.

Spencer, T., Biederman, J., Harding, M., Wilens, T., \& Faraone, S. (1995). The relationship between tic disorders and Tourette's syndrome revisited. Journal of the American Academy of Child \& Adolescent Psychiatry, 34, 1133-1139.

Spencer, T., Biederman, J., Coffey, B., Geller, D., Wilens, T., \& Faraone, S. (1999). The 4-year course of tic disorders in boys with attention-deficit/hyperactivity disorder. Archives of General Psychiatry, 56, 842-847.

Spencer, T. J., Biederman, J., Faraone, S., Mick, E., Coffey, B., Geller, D., et al. (2001). Impact of tic disorders on ADHD outcome across the life cycle: findings from a large group of adults with and without ADHD. American Journal of Psychiatry, 158, 611-617.

Stevens, J. (2002). Applied multivariate statistics for the social sciences. Mahwah: Erlbaum.

Stoddart, S. D., Craddock, N. J., \& Jones, L. A. (2007). Differentiation of executive and attention impairments in affective illness. Psychological Medicine, 37, 1613-1623.

Tewes, U., Rossmann, P., \& Schallberger, U. (1999). HamburgWechsler-Intelligenztest für Kinder-Dritte Auflage. Manual. Bern: Hans Huber.

Unnewehr, S., Schneider, S., \& Margraf, J. (1995). Kinder DIPSDiagnostisches Interview bei psychischen Störungen im Kindesund Jugendalter.

Van Zomeren, A. H., \& Brouwer, W. H. (1994). Clinical neuropsychology of attention. New York: Oxford.

Vicario, C. M., Martino, D., Spata, F., Defazio, G., Giacchè, R., Martino, V., et al. (2010). Time processing in children with Tourette's syndrome. Brain and Cognition, 73, 28-34.

Wechsler, D. (1991). Manual for the Wechsler intelligence scale for children (3rd ed.). San Antonio: Psychological Corporation.

Weiß, R. H. (1998). Grundintelligenztest Skala 2 (CFT 20) mit Wortschatztest (WS) und Zahlenfolgentest (ZF). Handanweisung (4. überarbeitete Auflage). Göttingen: Westermann Test.

Willcutt, E. G., Doyle, A. E., Nigg, J. T., Faraone, S. V., \& Pennington, B. F. (2005). Validity of the executive function theory of attention-deficit/hyperactivity disorder: a meta-analytic review. Biological Psychiatry, 57, 1336-1346.

World Health Organization. (1993). The ICD-10 classification of mental and behavioural disorders: Diagnostic criteria for research. Geneva: World Health Organization.

Yordanova, J., Heinrich, H., Kolev, V., \& Rothenberger, A. (2006). Increased event-related theta activity as a psychophysiological marker of comorbidity in children with tics and attention-deficit/ hyperactivity disorders. Neuroimage, 32, 940-955. 